\title{
Vardiya Çizelgeleme Problemi ve Bir Örnek Uygulama
}

\author{
Emre VARLI, Tamer EREN \\ Endüstri Mühendisliği, Kırıkkale Üniversitesi, Kırıkkale, Türkiye \\ ef.varli@gmail.com, tamereren@gmail.com \\ (Geliş/Received:12.10.2016; Kabul/Accepted:12.01.2017) \\ DOI: $10.17671 /$ gazibtd.309302
}

\begin{abstract}
Özet- Günümüzde birçok işletme daha iyi bir hizmet veya üretim yapmak için birbirleriyle rekabet içerisindedir. Bu nedenle her işletme varlıklarını sürdürebilmek ve verimliliğini artırmak için çalıştırdığı personelin istek ve tercihlerini dikkate alarak müşterilerine daha kaliteli ürün veya hizmet sağlayabilirler. Genellikle personel memnuniyeti için kullanılan personel çizelgeleme, son yıllarda popüler bir problem haline gelmiştir. Uygulama alanı çok geniş bir yelpazeye sahip olduğundan çok yoğun bir şekilde kullanılmaktadır. Bu çalışmada, bir fabrikada çalışan şefleri ilk olarak Analitik Hiyerarşi Prosesi (AHP) tekniğinden faydalanarak belirli kriterler yardımıla kıdem seviyelerine ayırdıktan sonra fabrikanın her bir vardiya için ihtiyaç duyduğu işgücünü karşılamak, planlanan dönem boyunca şeflere verilen izin günlerini düzenlemek, her bir şefin toplam işgücünü dengeli ve adaletli bir şekilde dağıtmak ve en önemlisi kıdem seviyelerini kullanarak niteliği çok olan şefler ile niteliği az olan şefleri aynı vardiyaya olabildiğince atanması gibi problemlerin çözümü için bir model geliştirilmeye çalışılmıştır.
\end{abstract}

Anahtar Kelimeler - Kıdem Seviyeleri, Analitik Hiyerarşi Prosesi, Vardiya Çizelgeleme, Hedef Programlama

\section{Shift Scheduling Problems and A Case Study}

\begin{abstract}
Many businesses nowadays to make a better service or production are in competition with each other. Therefore, to maintain their existence taking into consideration the wishes and the preferences of each business and staff to improve the efficiency of the run can provide a higher quality product or service to customers. Staff scheduling generally used for staff satisfaction so the problem in recent years has become a popular. Application area of a very broad range is used very intensively. In this study, a factory employee chefs firstly Analytic Hierarchy Process (AHP) after separating the seniority level with the help of specific criteria, taking advantage of the technique to meet the labor force needed for each shift of the factory, during the planning period to organize the day allowed the chef, balanced and equitable total workforce of each chief a way to distribute and most importantly the skills of the chefs with less seniority levels using the very skills of the chief has attempted to develop a model for the solution of problems such as assigning the same shift.
\end{abstract}

Keywords - Seniority Level, Analytical Hierarchy Process, Shift Scheduling, Goal Programming

\section{GIIRIŞ (INTRODUCTION)}

Son yıllarda işletmeler, topluma daha iyi bir hizmet vermek adına birbirleriyle rekabet içerisindedir. $\mathrm{Bu}$ rekabet ortamında ayakta kalabilmek ve insanların beklentilerini karşılayabilmek için herhangi bir işletmede çalışan personelin verimliliğinin ve kalitesinin arttırmasına yönelik çalışmalar yapılması gereklidir. Personel memnuniyetinin arttrilmasinda personel çizelgelemenin önemi çok büyüktür. Çünkü personel çizelgeleme, çalışan personelin ihtiyaç ve tercihleri doğrultusunda bir model oluşturarak hem çalışan personelin hem de ilgili işletmenin planlı ve sistemli bir şekilde üretim veya hizmet yapabilmesini sağlamaktadır.
Personel çizelgelemenin bir alt problemi olan vardiya çizelgeleme problemi, geçmişten günümüze kadar yapılan çalışmalar incelendiğinde en çok üzerinde çalışılan bir problem olarak karşımıza çıkmaktadır. Vardiya çizelgeleme problemi sanayilerde, işletmelerde, hastanelerde ve buna benzer birçok yerde karşımıza çıkan önemli bir problemdir. Bu problemin çözümünde, çalışan personelin vardiyalara adaletli ve dengeli bir şekilde dağıtarak onların insanlara daha iyi bir hizmet vermesi amaçlanmaktadır. Bunlara ek olarak vardiya çizelgeleme problemi, çalışan personelin yanı sıra iş̧̧i ücretleri, fazla mesailer, mola saatleri gibi konularda iyileştirmeler yaparak kurum ve kuruluşların gelirlerinde de artış sağlamaktadır. 
Çalışan personele uygun bir planlama yapmak için personel tercihlerini, niteliklerini ve buna benzer birçok kriter hesaba katılmalıdır. Böylelikle el ile yapılan çizelgelerin pek bir öneminin kalmaması ile birlikte analitik yöntemlerin kullanılması gerekmektedir. Ek olarak personele uygun planın yapılması verimliliği artıracak ve müşterilerin istekleri daha çabuk karşılanacaktır [1].

Hedef programlama son yillarda yaygın olarak kullanılan çok ölçütlü karar verme tekniklerinden biridir. Hedef programlamada amaç, birbirleriyle çakışan birçok hedefin arasından istenilen sonuçları elde etme çabasıdır. Hedef programlama matematiksel modellemede kullanılan tekniklerdeki gibi optimal sonucu bulmayla ilgilenmez. Hedef programlamada istenilen hedeflerdeki sapma değişkenlerini en küçükleyerek hedefleri olabildiğince gerçekleştirme arzusudur.

Çalışmada kullanılan başka bir yöntemde Analitik Hiyerarşi Prosesi (AHP) yöntemidir. İlk defa Satty tarafından kullanılan çok ölçütlü karar verme yöntemlerinden biridir. Bu yöntemde karar hiyerarşisi tanımlandığında kararları etkiyen faktörlerin, karar aşamasında yüzde dağılımlarını veren bir karar verme yöntemi olarak açıklanabilir.

$\mathrm{Bu}$ çalışmada bir fabrikada çalışan şefleri çok kriterli karar verme yöntemlerinden biri olan Analitik Hiyerarşi Proses (AHP) yöntemi ile kıdemlerine göre sınıflandırarak ve daha sonra 28 günlük çalışma periyodunda fabrikanın ihtiyaç duyduğu iş gücünü karşılamak, şefleri dengeli bir şekilde vardiyalara atamak, şeflere verilen izin günlerini düzenlemek ve en önemlisi kıdem seviyelerine göre ayrılan şeflerin her vardiyaya atanırken genellikle en niteliklisi ile en niteliksizi aynı vardiyaya atayarak fabrikanın çalışma temposunu artırmak ve kıdemi daha çok olan şefler ile daha az olan şefler arasında düzeni sağlamak amaçlanmıştır. Hedef programlama ile kıdemli-kıdemsiz ataması, aylık işgücü dağılımının eşit olması, modelin daha sistemli ve gerçeğe uygun olması için kullanılan sapma değişkenleri minimize edilerek model kurulmuştur.

Yapılan bu çalışmada, ikinci bölümde vardiya çizelgeleme, üçüncü bölümde hedef programlama, dördüncü bölümde analitik hiyerarşi proses (AHP), beşinci bölümde literatür araştırması, altıncı bölümde yapılan uygulama ve son olarak yedinci bölümde de yapılan uygulamanın sonuçları anlatılmıştır.

\section{VARDIYYA ÇİZELGELEME (SHIFT SCHEDULING)}

Vardiya çizelgeleme, personel çizelgeleme problemleri arasında en çok ele alınan problem çeşidi olarak gösterilebilir. Yapılan çalışmalar incelendiğinde vardiya çizelgeleme problemi neredeyse bütün çalışmalarda ele alınmıştır. Fabrikalar veya işletmeler vardiya çizelgeleme ile personel için bir çalışma planı yaparak personel memnuniyeti, verimliliği, işletme giderleri ve zaman gibi konularda iyileştirmeler yapabilirler. Ek olarak çalışılan yerin kendine özgü benimsediği kuralları modele ekleyerek gerçeğe uygun ve çalışma prensiplerini yerine getirerek farklı çizelgelemeler yapılabilir.

Personel çizelgeleme problemleri ilgili işyerinin kuralları doğrultusunda, her çalışanın çalışma tercihlerini dikkate alarak çeşitli hizmet türlerini karşılamak adına nitelikli personeller tahsis edilmesi gereklidir. $\mathrm{Bu}$ problemler bazen çözülmesi güç, kısıtlı optimizasyon problemleridir [2].

Genel olarak bu konularda yapılan ilk çalışma Edie ve Dantzing tarafindan 1950 yıllarındadır. Dantzing ele aldığı çalışmasında araç kabin operatörleri için bir çizelgeleme yapmış ve çözüm olarak liner programlamayı kullanmıştır. Çalışmasında gerekli iş gücü miktarının olması gerektiği kadar ya da bundan daha fazla olmas1 koşulu ile maliyeti en küçüklemeyi istemiştir [3-4].

Vardiya çizelgelemenin kullanıldığı alanlardan söz edilecek olursa kamu hizmetleri, fabrika, işletme, turizm ve otelcilik, hastane, demiryolu, havayolu, güvenlik hizmetleri, çağrı merkezleri, perakende ve askeri sistemler alanlarında vardiya çizelgeleme yoğun bir şekilde kullanılmaktadır. Sektör olarak bu kadar geniş bir yelpazeye sahip olması vardiya çizelgelemenin yaşantımızda ne kadar önemli bir yere sahip olduğunu da göstermektedir.

Vardiya çizelgeleme probleminin çözümü için matematiksel modellemelerden, sezgisel algoritmalardan veya her ikisini birden kullanarak model oluşturulur. Matematiksel modeller: doğrusal programlama, tam sayılı programlama, hedef programlama, dinamik programlama ve sezgisel algoritmalar: genetik algoritma, tabu arama yöntemi, stokastik programlama bu yöntemlerden birkaçı olarak gösterilebilir.

\section{HEDEF PROGRAMLAMA (GOAL PROGRAMMING)}

Hedef programlama çok kriterli karar verme modellerinin bir türüdür. Modeli oluşturulurken olmazsa olmaz kısıtlara ek olarak hedeflenen kısıtlara gevşek değișkenler eklenerek modelin kısıtları yazılır. Buradaki amaç oluşturulan hedef kısıtlarındaki gevşek değişkenlerin minimize edilmesi işlemidir. Diğer modellemelerde tek bir amaç fonksiyonu kullanılırken hedef programlama ile oluşturulan modellerde birden çok amaç aynı anda veya sirasıyla kullanılır yani hedef programlama birden fazla amacı birer kısıt haline dönüştürerek kısıtların önem derecelerine göre siralayarak veya her birini ağırlıklandırarak bu kısıtların sapmalarını amaç fonksiyonunda en küçükleme ile hedefe ulaşılmasını sağlar.

Hedef programlama her amacin verilen hedeflere mümkün olduğunca ulaşmasını amaçlar ve hedefteki sapmaları minimize etmektir [5].

Hedef programlama ile ilgili ilk olarak 1955' te Charnes ve arkadaşları çalışmışlardır daha sonra 1961' de Charnes 
ve Cooper bu modellemeyi geliştirmek için uğraşmışlardır [6-7].

Hedef programlama matematiksel gösterimi aşağıdaki gibidir [8].

Minimize $Z=\sum_{i=1}^{k}\left(d_{i}^{+}+d_{i}^{-}\right)$

$\sum_{j=1}^{n} a_{i j} x_{j}+d_{i}^{+}+d_{i}^{-}=b_{i}$

$d_{i}^{+}+d_{i}^{-}=0$

$x_{j}, d_{i}^{+}, d_{i}^{-} \geq 0$ $i=1 \ldots k \quad j=1 \ldots n$

Değişkenler

$x_{j}: j$. Karar değişkeni

$a_{i j}: i$. hedefin $j$. karar değişkeni katsayısı

$b_{i}: i$. hedef için ulaşılmak istenen değer

$d_{i}^{+}: i$. hedefin pozitif sapma değişkeni

$d_{i}^{-}: i$. hedefin negatif sapma değişkeni

Bu modellemeyi kullanarak personel çizelgeleme ile ilgili literatürde pek çok çalışma mevcuttur. Yapılan çalışmalarda genellikle vardiya çizelgeleme problemi ele alınmıştır ve buna ek olarak ekip çizelgeleme, izin günlerini çizelgeleme, iş gücü çizelgeleme gibi problemlerin çözümünde de hedef programlama metodu kullanılmıştır. Yapılan bazı çalışmalar şunlardır: Aly ve Louly [9] telekominasyon merkezinde personel çizelgeleme problemi, Azaiez ve Sharif [10] hedef Programlama ile hemşire çizelgeleme, Bektur ve Hasgül [11] kıdem seviyelerine göre iş gücü çizelgeleme, Chu [12] Hong Kong Uluslararası hava alanında çalışan ekibin çizelgelenmesi, Elomri vd. [13] bir hastanede çalışan stajyer doktorlar için hedef programlama, Hung-Tso vd. [14] ekip atama problemi, Sulak ve Bayhan [15] tur çizelgeleme problemi, Topaloğlu [16] çalışanların çalışma tercihlerini dikkate alarak tur çizelgeleme problemi, hedef programlama ile yapılan çalışmalara örnek olarak verilebilir.

\section{ANALITIKK HIYYERARŞİ PROSESİ (ANALYTICAL HIERARCHY PROCESS)}

Analitik Hiyerarşi Proses (AHP) karar verme problemine göre belirlenen kriteri kullanarak bu kriterlerin kendi aralarındaki önem ağırlıklarını elde etmede ve kriterleri etkiyen faktörler arasında bir hiyerarşi oluşturmada kullanılan bir yöntem olarak tanımlanabilir. AHP yöntemiyle ile ilgili ilk çalışma Myers ve Alpert tarafindan 1968 yılında yapılmıştır. Saaty, 1977 yılında bu yöntemi bir model haline getirerek karar verme problemleri için daha kullanışlı hale getirmiştir [17]. AHP yöntemini kullanmak için aşağıdaki adımlar dikkate alınmalıdır.

\subsection{Karar Verme Probleminin Tanımlanması (Defining Decision Making Problem)}

$\mathrm{Bu}$ bölümde yapılması gereken iki adım vardır. Birinci adımda kriterler, ikinci adımda ise kriterleri etkileyen faktörler belirlenir. Kriterlerin sayısı a ile faktörlerin sayısı da b ile sembolize edilmiştir. Problem için kullanılan kriterlerin ve faktörlerin çok iyi tanımlanması gerekmektedir çünkü birbirleri ile karşılaştırma yapılırken doğru ve tutarlı bir sonuç vermesi açısından önemlidir.

\subsection{Kriterler ve Faktörler Arası Karşılaştırma Matrislerinin Oluşturulmasl (Creating Criteria and Factor} Comparison Matrices)

Kriterler ve faktörler sayıları kadar için aşağıda verilen matris oluşturulur ve $a \times a$ boyutta karesel bir matristir. Kullanılan her bir kriter veya faktör kendisi ile karşılaştırılamayacağından dolayı matristeki köşegenler 1 değerini alır.

$M=\left[\begin{array}{cccc}m_{11} & m_{12} & \ldots & m_{1 a} \\ m_{21} & m_{22} & \ldots & m_{2 a} \\ \cdot & \cdot & & \cdot \\ \cdot & \cdot & & \cdot \\ m_{a 1} & m_{a 2} & \ldots & m_{a a}\end{array}\right]$

Kriterlerin ve faktörlerin karşılaştırmaları, önem değerleri dikkate alınarak puanlandırma yapılır. Puanlandırma işlemi Saaty’nin 1990'da kullandığı önem skalasına göre yapılmıştır [18].

Karşılaştırmalar yapılırken matristeki köşegen değerlerinin üstünde kalan yerlere puanlar verilir. Köşegen değerlerinin altında kalan yerlerin alacağ puanlarda (4.1)'deki formül yardımıyla elde edilir.

$m_{j i}=\frac{1}{m_{i j}}$

4.3. Kriterlerin ve Faktörlerin Yüzde Önem Dă̆llımlarının Belirlenmesi (Determination of Percentage Distribution of Importance Factors and Criterias )

Kriterlerin ve faktörlerin yüzde önem dağılımlarının bulunabilmesi için karşılaştırma matrislerinden yararlanılır. Tüm matrisler için aynı işlemler yapılır. Bu işlemler sırasıyla şu şekildedir. Her bir matrisin sütun vektörleri toplanır daha sonra sütun vektörlerinin toplamı matristeki her bir değere bölünerek başka bir matris elde edilir. Elde edilen matrise $\mathrm{N}$ matrisi veya Normalize Matris denilmiştir.

Her bir sütun vektörünün hesaplanmasında aşağıdaki (4.2) formülünden yararlanılır.

$n_{i j}=\frac{m_{i j}}{\sum_{i=1}^{a} m_{i j}}$ 
$N=\left[\begin{array}{cccc}n_{11} & n_{12} & \ldots & n_{1 a} \\ n_{21} & n_{22} & \ldots & n_{2 a} \\ \cdot & \cdot & & \cdot \\ \cdot & \cdot & & \cdot \\ n_{a 1} & n_{a 2} & \ldots & n_{a a}\end{array}\right]$

Bir sonraki adım olan tutarlılık ölçülerinin bulunabilmesi için öncelik vektörlerini elde etmemiz gereklidir. Öncelik vektörü V matrisi ile gösterilmiştir. Öncelik matrislerinin her biri aşağıda verilmiş olan formül (4.3) ile elde edilir.

$v_{i j}=\frac{\sum_{j=1}^{a} n_{i j}}{a}$

V öncelik vektörü aşağıda gösterilmiştir.

$V=\left[\begin{array}{c}v_{1} \\ v_{2} \\ \cdot \\ \cdot \\ v_{a}\end{array}\right]$ 4.4. Kriterler ve Faktör Klyaslamalarındaki Tutarlılık
Ölçüsü (Consistency Measures of Criteria and Factor Benchmarks)

AHP yöntemi çok sistematik bir yöntem olarak gözükse de yapılan her karşılaştırmanın tutarlı olması istenmektedir. Bunun içinde tutarlılık oranlarını (CR) elde edilerek yapılan karşılaştırmaların doğru ve sağlıklı sonuçlar vermesini arzu ederiz. Tutarlılık oranları bize bu açıdan bilgi vermektedir.

Tutarlılık oranının elde edilmesi için aşağıda verilen adımlar izlenir:

- M karşılaştırma matrisi ile V öncelik vektörü çarpılmıştır ve elde edilen yeni sütun vektörü $Z$ ile gösterilmiştir.

- $\quad$ Z sütun vektörü ile V sütun vektörü değerleri karşılıklı bölünerek temel değer (E) elde edilmiştir. Temel değerlerin elde edilmesi için formül (4.4)'ten yararlanılmıştır.

- Temel değerlerin aritmetik ortalaması alınarak öz değer yani $(\lambda)$ elde edilmiştir. Öz değerin hesaplanması için formül (4.5)'ten yararlanılmıştır.

- $\quad$ Öz değerlerler hesaplandıktan sonra tutarlılık göstergesi (CI) değeri formül (4.6) kullanılarak bulunmuştur.

- Son aşamada ise tutarlık göstergesi (CI) ile Tablo 1'de verilen rassal gösterge (RI) değerlerinden uygun olan değer seçilerek birbirlerine bölünmüş ve tutarlılık oranı elde edilmiştir. Tutarlılık oranın hesaplanması için formül (4.7)'den faydalanılmıştır. Rassal göstergede uygun değer, kriter sayısına göre seçilir.
$Z=\left[\begin{array}{cccc}m_{11} & m_{12} & \ldots & m_{1 a} \\ m_{21} & m_{22} & \ldots & m_{2 a} \\ \cdot & \cdot & & \cdot \\ \cdot & \cdot & & \cdot \\ m_{a 1} & m_{a 2} & \ldots & m_{a a}\end{array}\right] \times\left[\begin{array}{c}v_{1} \\ v_{2} \\ \cdot \\ \cdot \\ v_{a}\end{array}\right]$

$$
\begin{aligned}
& E_{i}=\frac{m_{i}}{v_{i}} \quad(\mathrm{i}=1,2, \ldots, \mathrm{a}) \\
& \lambda=\frac{\sum_{i=1}^{a} E_{i}}{a} \\
& C I=\frac{\lambda-a}{a-1}
\end{aligned}
$$

Tablo 1. RI Değerleri (RI Values)

\begin{tabular}{|c|c|c|c|c|c|c|c|}
\hline $\mathbf{n}$ & $\mathbf{1}$ & $\mathbf{2}$ & $\mathbf{3}$ & $\mathbf{4}$ & $\mathbf{5}$ & $\mathbf{6}$ & $\mathbf{7}$ \\
\hline $\mathbf{R I}$ & 0 & 0 & 0,58 & 0,9 & 1,12 & 1,24 & 1,32 \\
\hline $\mathbf{n}$ & $\mathbf{8}$ & $\mathbf{9}$ & $\mathbf{1 0}$ & $\mathbf{1 1}$ & $\mathbf{1 2}$ & $\mathbf{1 3}$ & $\mathbf{1 4}$ \\
\hline $\mathbf{R I}$ & 1,14 & 1,45 & 1,49 & 1,51 & 1,48 & 1,56 & 1,57 \\
\hline
\end{tabular}

$C R=\frac{C I}{R I}$

Tutarlılık oranı eğer 0,10 'dan küçükse, bu yapılmış olan karşılaştırmaların tutarlı olduğunu göstermektedir. Eğer 0,10'dan büyükse karşılaştırma matrislerinde bir tutarsızlık olduğunu ve yeniden gözden geçirilmesi gerektiği sonucuna varılır.

\subsection{Karar Noktalarındaki Sonuç Dağılımının Bulunması (Finding Results in Decision Point Distribution)}

$\mathrm{Bu}$ bölümde her bir faktör için elde edilmiş V öncelik vektörleri birleştirilerek tek bir matris haline getirilir. $\mathrm{Bu}$ matris Q matrisi olarak aşağıda gösterilmiştir.

$Q=\left[\begin{array}{cccc}v_{11} & v_{12} & \ldots & v_{1 a} \\ v_{21} & v_{22} & \ldots & v_{2 a} \\ \cdot & \cdot & & \cdot \\ \cdot & \cdot & & \cdot \\ v_{b 1} & v_{b 2} & \ldots & v_{b a}\end{array}\right]$

Son aşamada ise faktörler için elde edilen öncelik vektörlerinin birleştirilmesi ile oluşturulmuş $\mathrm{Q}$ matrisi ve kriterler için elde edilen öncelik vektörünün çarpılması sonucu karar noktalarındaki sonuç dağılımı elde edilmiştir.

Sonuç dağılımı aşağıda verilen T matrisiyle gösterilmiştir. 


$$
T=\left[\begin{array}{cccc}
v_{11} & v_{12} & \ldots & v_{1 a} \\
v_{21} & v_{22} & \ldots & v_{2 a} \\
\cdot & \cdot & & \cdot \\
\cdot & \cdot & & \cdot \\
v_{b 1} & v_{b 2} & \ldots & v_{b a}
\end{array}\right] \times\left[\begin{array}{c}
v_{1} \\
v_{2} \\
\cdot \\
\cdot \\
v_{a}
\end{array}\right]=\left[\begin{array}{c}
t_{11} \\
t_{21} \\
\cdot \\
\cdot \\
t_{b 1}
\end{array}\right]
$$

\section{LITERATÜR ARAŞTIRMASI (LITERATURE RESEARCH)}

$\mathrm{Bu}$ konu ile alakalı literatürde pek çok çalışma vardır. Çalışma alanı geniş olduğundan genel çalışma prensiplerinin dışında çok farklı kısıtlamalar ve modeller kullanarak gerçek hayat problemleri ele alınmıştır. Vardiya çizelgeleme ile alakalı yapılan bazı çalışmalar şunlardır:

Topaloğlu ve Özkarahan [1] çalışmalarında esnek bir planlama kullanılarak bir model geliştirilmiş ve hedef programla ile model çözülmüştür. Aly ve Louly [9] çalışmalarında bir telekominasyon şirketinde çalışan mühendislerin vardiyalara atanması, belirli izin günlerinin belirlenmesi ve şirketin çalışma prensipleri doğrultusunda birkaç hedef kısıtını gerçekleştirmek için bir model geliştirmişlerdir. Azaiez ve Al Sharif [10] çalışmalarında 0-1 liner programlama modeli kullanılarak hemşire çizelgeleme problemi geliştirmişlerdir. Geliştirilen modelde hem hastanenin istekleri hem de hemşirelerin tercihleri dikkate alınmıştır. Bektur ve Hasgül [11] çalışmalarında bir restoranda çalışan personeli kıdem seviyelerine ayırarak, personellere verilecek izinlerde k1dem seviyelerine göre atama yaparak ve tüm personelin isteklerini karşılayacak şekilde haftalık bir planlama gerçekleştirmişlerdir. Problemin çözümünde hedef programlama kullanmışlardır. Chu [12] çalışmasında Hedef Programlama kullanılarak iş gücü planlaması yapmıştır. Çizelgeleme yapılırken hem esnek, tatmin edici bir çalışma koşulları, boşta olan vardiyalar minimize edilmek hedeflenmiştir. Çalışmayı Hong Kong Uluslararası Havayollarındaki personellerin ataması ve planlanması için yapmıştır. Elomri vd. [13] çalışmalarında belirli bir hastanede çalışan stajyer doktorların Onkoloji ve Hematoloji bölümlerine dengeli bir şeklide atanmaları için bir çalışma sunmuşlardır. Hung-Tso vd. [14] çalışmalarında güney Tayvan'da bir mağazada müşteri hizmetleri bölümünde hazırlanan ekip çizelgeleme problemine çözüm bulmayı amaçlamışlardır. Çalıșmada müşterilere verilecek hizmet süreleri bulanık küme ile belirlenmiş ve çözüm için hedef programlama kullanmışlardır. Sulak ve Bayhan [15] çalışmalarında bir hastanedeki hemşirelerin 3 vardiya ve farklı çalıșma saatlerini dengeli bir şekilde hemşirelerin atanması için bir model belirlemişlerdir. Problemin çözümünde hedef programlama kullanmışlardır. Topaloğlu [16] çalışmasında farklı klinik ortamlarında çalışan stajyer doktorların planlanması için yapmıştır. Stajyer doktorların kıdem seviyeleri dikkate alınarak problem karışık tam sayılı programlama ile çözmüştür. Azmat vd. [19] çalışmalarında tam sayılı programlama ile vardiya iş gücü çizelgeleme problemi ele alınmıştır. Yıllık çalışma saati İsviçre'nin yasal kanunları kullanılarak uygulanmıştır. Volgenant [20] çalışmasında personellerin kıdem seviyelerine ayırarak nitelikli ve niteliksiz personellerin gerekli iş gücüne atanmasını ele almıştır. Alfares [21] çalışmasında 4 tip izin günleri kısıtları ile üç günlük çalışma haftasında çizelgeleme problemi ortaya koymuştur: Her işçinin verilmiş dört izin gününde en az ikisi ardışık olmalıdır. Hafta sonu tatillerinde yeteri kadar işçi çalıştırmaktır. Maksimum çalışma esnekliği her çalışan için birbirini izleyen dört iş günüdür. Hafta sonu çalışmalarında ardışık haftaların maksimum sayısını belirlemektir. Matematiksel modelde ilk önce problemin yapısı askeri iş gücünü belirlemektir daha sonra iş gücünü kısıtlamak için tam sayılı programlama modeli kullanmıştır. Son olarak birden fazla haftanın çizelgelenmesinde hafta sonu çalışmaları ile ardışık hafta sayısını minimize etmek veya sınırlamakta tüm kısıtları karşılamak için bir model oluşturmuştur. Al-Yakoob ve Sherali [22] çalışmalarında Kuveyt Ulusal Petrol şirketinde benzin istasyonlarında çalışan işçilerin atama problemleri üzerinde çalışmışlardır. Kuveyt'teki yaklaşık 86 istasyona işçilerin atanması için çizelgeleme düzenlenmişler ve bu problemi iki aşamalı bir yaklaşım ile benimsemişlerdir, ilk aşama işçilerin istasyonlara atanması ikinci aşama her işçinin tatil günlerinin ve vardiyalarının belirlenmesidir. Bu iki aşamalı yaklaşımda çalışanların tercihleri dikkate alınarak çalışanlar için günlük program sağlanmıştır. Elle yapılan çizelgeleme genellikle düzensizlik, çalışanlar arasında ön yargı ve iş memnuniyetsizliği gibi problemler ortaya çıkmıştır, yeni oluşturulan karar destek modeli ile bu gibi problemlerin önüne geçmeyi amaçlamışlardır. Seckiner vd. [23] çalışmalarında sıkı bir çalışma haftasında hiyerarşik iş gücü sorunu için tam sayılı programlama modeli geliştirmişlerdir. Çalışmada Billionet tarafından geliştirilen tam sayılı programlama kullanarak çözümü elde etmişlerdir. Sinreich ve Jabali [24] çalışmalarında doğrusal optimizasyon ve sezgisel yöntemler simülasyon tabanlı bir algoritma iş vardiyaları, kaynak planlanması gibi çalışmalar için kullanmışlardır. Sungur [25] çalışmasında her bir çalışma günü ve saati için ihtiyaç duyulan iş gücü sayısını minimum maliyetle karşılamak şartıyla, her bir tura atanarak iş gücü sayısının belirlenmesini amaçlamıştır. Çalışma bir güzellik salonunda ele alınmış ve problemin çözümünde karma tam sayılı programlama kullanmıştır. Sungur [26] çalışmasında Billionet Modeli kullanılarak hiyerarşik iş gücü çizelgeleme problemi çözmek istemiştir. Rong [27] çalışmasında birçok literatürde ve çalışmada olan haftalık iş günlerinin planlanmasının aksine, hafta sonu tatil günlerini dikkate alarak bir tur çizelgeleme oluşturmak istemiştir. Problemin çözümünde tam sayılı programlama kullanmıştır. Bağ vd. [28] çalışmalarında hemşire çizelgeleme problemini ele almışlardır. Problemin çözümünde tamsayılı hedef programlama kullanmışlar ve hedeflerin ağırlıklarını belirlemek için analitik ağ prosesi (ANP) kullanmışlardır. Çalışmayı Kırıkkale'deki bir devlet hastanesinde uygulamışlardır. Kassa ve Tizazu [29] çalışmalarında Avanti Blue Nil otelinde çalışan 5 personel için haftalık çalışma günlerini belirlemek adına tam sayılı programlama kullanmışlardır. Öztürkoğlu ve Çalışkan [30] çalışmalarında hemşirelere çalışma saatlerinin başlangıcında esneklik sağlayarak hemşirelerin 
memnuniyetini artırmak ve aylık işgücü planının yapılması için bir tam sayılı programlama modeli önermişlerdir. Hidri ve Labidi [31] çalışmalarında yoğun bakım ünitesindeki 3 blokta çalışan hemşireleri belirli gruplara ayırarak ihtiyaç duyulan hemşire sayılarını atama problemini çözmek adına farklı kısıtları kullanarak bir tam sayılı programlama modeli geliştirmişlerdir. Unal ve
Eren [32] çalışmalarında hedef programlama kullanarak nöbet çizelgeleme problemini ele almışlardır.

\section{UYGULAMA (APPLICATION)}

Bu çalışmada kullanılan akış şeması aşağıda verilmiştir

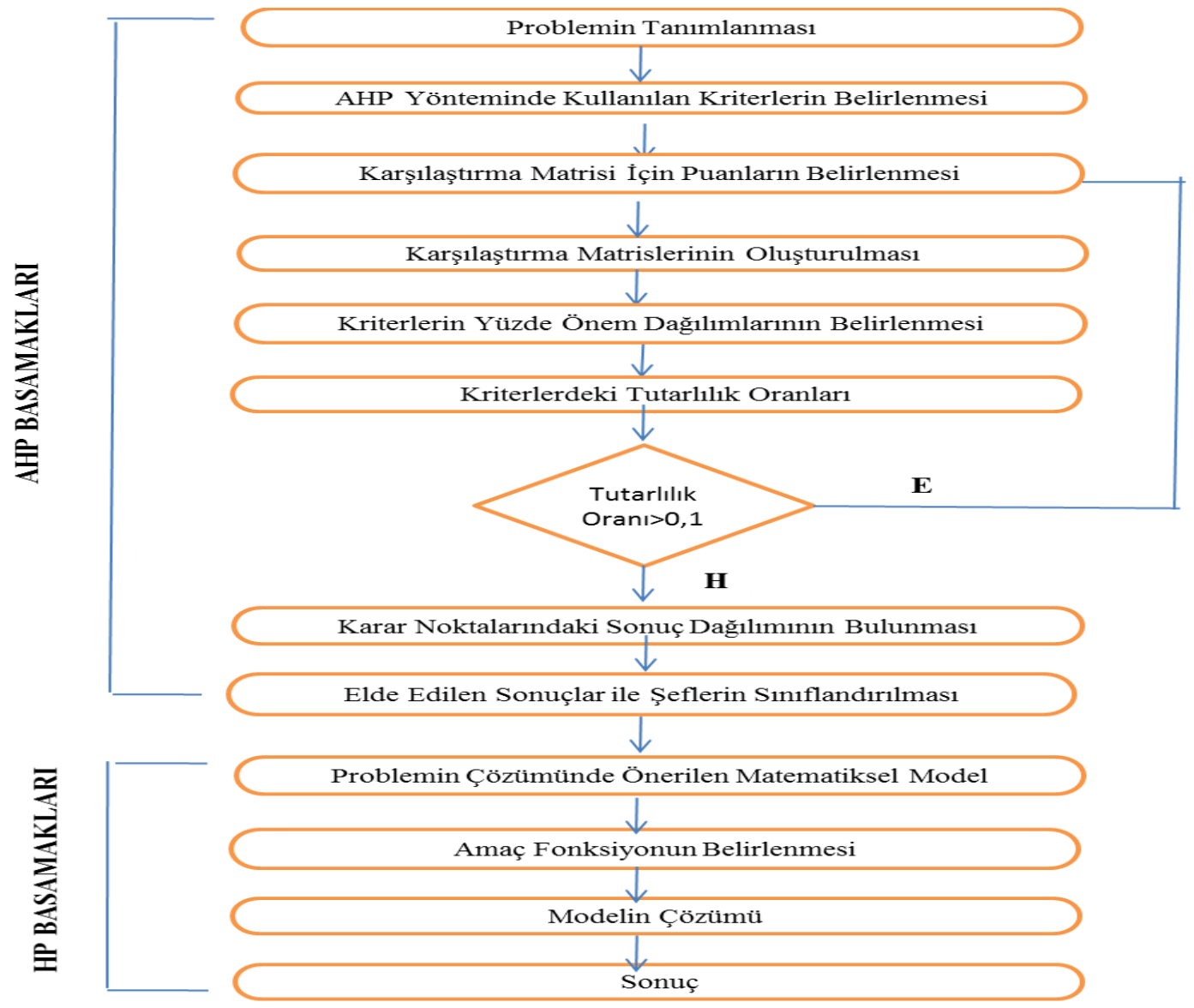

Șekil 1. AHP ve hedef programla yöntemiyle vardiya atama problemi (Shift assignment problem with AHP and goal programming methods)

\subsection{Problemin Tanımlanması (Defining the Problem)}

$\mathrm{Bu}$ çalışmada, 3 vardiya üretim yapan bir fabrikada çalışan şefleri ilk olarak Analitik Hiyerarşi Prosesi (AHP) yönteminden faydalanarak belirli kriterler yardımıyla kıdem seviyelerine ayırdıktan sonra fabrikanın her bir vardiya için ihtiyaç duyduğu işgücünü karşılamak, planlanan dönem boyunca şeflere verilen izin günlerini düzenlemek, her bir şefin toplam işgücünü dengeli ve adaletli bir şekilde dağıtmak ve en önemlisi kıdem seviyelerini kullanarak niteliği çok olan şefler ile niteliğ az olan şefleri aynı vardiyaya olabildiğince atamak gibi problemlerin çözümü için bir model geliştirilmeye çalışılmıştır.

Fabrikanın günlük çalışma periyodunda 3 vardiya vardır. Bunlar Sabah-S, Akşam-A, Gece-G olarak adlandırılmıştır. Her bir vardiyanın saat dilimleri ise Sabah (08:00-16:00), Akşam (16:00-00:00), Gece (00:0008:00). Sabah vardiyası için 3 şef, Akşam vardiyası için 3 şef, Gece vardiyası için de 1 şef atanmalıdır ve geriye kalan şefler ise ilgili günde izinlidir. Çalışmada Kasım ayındaki personel atamaları gerçekleştirilmiştir.

\subsection{AHP Yönteminde Kullanılan Kriterlerin Belirlenmesi (Determination of the criteria used in AHP Method)}

AHP analizinde kullanılan kriterler, fabrikada çalışan en az 10 yıl tecrübeli 3 atölye şefinin görüşleri dikkate alınarak belirlenmiş ve değerlendirilmiştir. Çalışmada şefleri becerilerine göre sınıflandırmak için kullanılan kriterler ve şeflerin bu kriterler için kullanılan bilgiler Tablo 2' de verilmiştir. 
Tablo 2. Kriterler ve Şeflere Ait Olan Bilgiler

(It belongs to the criteria and Chief Information)

\begin{tabular}{|c|c|c|c|c|c|}
\hline Şef / Kriterler & Tecrübe Yılı & Sertifika ve Eğitim & Aile Yapısı & Fabrikadaki Çalıştığı Yıl & İletişim Becerisi \\
\hline 1 & $10 \mathrm{y} 11$ & 2 adet & 2 çocuk & 3 y1l & 5 puan \\
\hline 2 & $10 \mathrm{y} 1 \mathrm{l}$ & 2 adet & 0 çocuk & $2 \mathrm{y} 1 \mathrm{l}$ & 3 puan \\
\hline 3 & $14 \mathrm{y} 11$ & 3 adet & 2 çocuk & 6 yil & 7 puan \\
\hline 4 & $7 \mathrm{y} 1 \mathrm{l}$ & 2 adet & 4 çocuk & $4 \mathrm{y} 1 \mathrm{l}$ & 1 puan \\
\hline 5 & 16 y1l & 4 adet & 1 çocuk & 14 y1l & 5 puan \\
\hline 6 & 9 y1l & 1 adet & 0 çocuk & 8 y1l & 9 puan \\
\hline 7 & $17 \mathrm{y} 1 \mathrm{l}$ & 3 adet & 2 çocuk & $11 \mathrm{y} 11$ & 5 puan \\
\hline 8 & $7 \mathrm{y} 1 \mathrm{l}$ & 2 adet & 3 çocuk & 3 yil & 3 puan \\
\hline 9 & $7 \mathrm{y} 1 \mathrm{l}$ & 1 adet & 1 çocuk & $1 \mathrm{y} 1 \mathrm{l}$ & 1 puan \\
\hline
\end{tabular}

Tecrübe Yılı: Her şefin toplam çalıştığı yılı göstermektedir.

Sertifika ve Ĕgitim: Her şef için iş hayatlarında aldıkları sertifikalar ve katıldıkları eğitim kurslarının toplamıdır.

Aile Yapısı: Şeflerin sahip olduğu çocuk sayısını göstermektedir.

Fabrikadaki Çalıştığı Yıl: Şeflerin sadece ilgili fabrikada çalıştığı yılı göstermektedir.
İletişim Becerisi: Şeflerin diğer çalışan personeller ile anlaşabilme ve çevresindekilere olan davranışları gibi konulardaki becerilerini puanlama yaparak dikkate alınmasıdır. Bu puanlama yapılırken şeflerden sorumlu olunan üst yönetimden bilgi alınarak değerlendirilmiştir.

6.3. Karşılaştırma Matrisi İçin Puanların Belirlenmesi (Determination of points for the Comparison Matrix)

Aşağıda verilen Tablo 3'te, Tablo 2' de verilen şeflere ait olan bilgiler karşılaştırma matrislerinde kullanılması için puanlara dönüştürülmüştür. $\mathrm{Bu}$ tabloda sadece iletişim beceresi kriterinde alınan değerler aynen kullanılmıştır.

Tablo 3. Şeflerin Kriterlere Göre Aldıkları Puanlar (Points they acquired according to the criteria of the Chief)

\begin{tabular}{|c|c|c|c|c|c|c|c|c|c|}
\hline $\begin{array}{l}\text { Tecrübe } \\
\text { Yılı }\end{array}$ & Puan & $\begin{array}{l}\text { Sertifika ve } \\
\text { Eğitim }\end{array}$ & Puan & $\begin{array}{c}\text { Aile } \\
\text { Yapısı }\end{array}$ & Puan & $\begin{array}{c}\text { Fabrikada Çalıştığı } \\
\text { Yıl }\end{array}$ & Puan & $\begin{array}{l}\text { İletişim } \\
\text { Becerisi }\end{array}$ & Puan \\
\hline $6^{\prime}$ dan az & 1 & 0 ile 1 arası & 3 & $\begin{array}{c}0 \text { ile } 1 \\
\text { aras } 1\end{array}$ & 3 & 0 ile 2 aras 1 & 1 & & 1 \\
\hline 7 ile 9 arası & 3 & 2 ile 3 aras 1 & 5 & $\begin{array}{c}2 \text { ile } 3 \\
\text { aras } 1\end{array}$ & 5 & 3 ile 5 aras 1 & 3 & & 3 \\
\hline $\begin{array}{c}10 \text { ile } 11 \\
\text { arası }\end{array}$ & 5 & 4 ile 5 aras 1 & 7 & $\begin{array}{c}4 \text { ile } 5 \\
\text { arası }\end{array}$ & 7 & 6 ile 8 aras 1 & 5 & & 5 \\
\hline $\begin{array}{c}12 \text { ile } 14 \\
\text { aras1 }\end{array}$ & 7 & $5^{\prime}$ ten fazla & 9 & $\begin{array}{l}5 \text { ' ten } \\
\text { fazla }\end{array}$ & 9 & 9 ile 11 aras 1 & 7 & & 7 \\
\hline 14 ' ten fazla & 9 & & & & & $12^{\prime}$ den daha fazla & 9 & & 9 \\
\hline
\end{tabular}

\subsection{Karşılaştırma Matrislerinin Oluşturulması}

Şefler için kullanılan kriterlerin kendi aralarında ve her bir kriter için bütün şefler dikkate alınarak EK1'de karşılaştırılmaları gösterilmiştir. $\mathrm{Bu}$ karşılaştırılmalar yapılırken Saaty' nin 1990 'da kullandığı önem skalası ile kullanılmıştır.

Karşılaştırma matrislerinde Tablo 2'deki bilgiler, Tablo 3 'teki puanlamalara dönüştürülerek oluşturulmuştur.

\subsection{Kriterlerdeki Tutarlılık Oranları}

Tablo 4'te AHP yönteminde kullanılan kriterin Tutarlılık oranları verilmiştir. 
Tablo 4.Tutarlılık Oranları (Consistency Ratios)

\begin{tabular}{|c|c|}
\hline & Tutarlıık Oranları \\
\hline Kriterler Arasında & 0,05 \\
\hline Tecrübe Yılı & 0,02 \\
\hline Sertifikalar ve Eğitim Kursları & 0,02 \\
\hline Aile Yapısı & 0,04 \\
\hline Fabrikadaki Çalıştığı Yıl & 0,03 \\
\hline İletişim Becerisi & 0,03 \\
\hline
\end{tabular}

6.6. Karar Noktalarındaki Sonuç Dağılımının Bulunması (Finding Results in Decision Point Distribution)

$\mathrm{Bu}$ aşama karar noktalarında oluşturulan öz vektörler birleştirilerek ve kriterler için elde edilen öz vektör çarpılarak sonuç dağılımı elde edilir. Çalışmada elde edilen sonuçlar aşağıda verilmiştir. Tablo 4 'teki sonuçlara göre her bir kriter için elde edilen tutarlılık oranı 0,10 'dan küçüktür. Dolayısıyla tutarlı bir sonuç elde edilmiştir.

Tablo 5. Şeflerin Becerilerine Göre Aldıkları Puanlar (Points they received by Chief of skills)

\begin{tabular}{|c|c|c|}
\hline Şefler & Sonuç & Aldıkları Puan \\
\hline $\mathbf{1}$ & 0,09 & 3 \\
\hline $\mathbf{2}$ & 0,07 & 3 \\
\hline $\mathbf{3}$ & 0,14 & 5 \\
\hline $\mathbf{4}$ & 0,06 & 2 \\
\hline $\mathbf{5}$ & 0,27 & 10 \\
\hline $\mathbf{6}$ & 0,07 & 2 \\
\hline $\mathbf{7}$ & 0,21 & 8 \\
\hline $\mathbf{8}$ & 0,06 & 2 \\
\hline $\mathbf{9}$ & 0,03 & 1 \\
\hline
\end{tabular}

Tablo 5'te puanlar belirlenirken 1 ile 10 arası puanlama yapılması için her bir değer ilk olarak 100 ile daha sonra da 10/27 ile çarpılmıştır.

6.5.Elde Edilen Sonuçlar ile Şeflerin Sınıflandırılması (Classification of the Chief Obtained Results)

Tablo 5'ten yararlanılarak şefler şu şekilde sınıflandırılmıştır.

Tablo 6. Niteliklerine Göre Şeflerin Sınıflandırılması (Classification of Chief according to their qualities)

\begin{tabular}{|c|c|c|}
\hline Nitelikler & Şefler & Puan \\
\hline Çok Nitelikli & $5,7,3$ & 5 \\
\hline Orta Nitelikli & 1,2 & 3 \\
\hline Az Nitelikli & $4,6,8,9$ & 1 \\
\hline
\end{tabular}

Oluşturulan matematiksel modelde Tablo 6'teki puanlar kullanılmaktadır. Yeniden bir puan verilmesinin sebebi modelin çözümünde istenilen, niteliği çok olan şefler ile az olan şefler aynı vardiyaya atanması probleminin daha sağlıklı ve istenilene uygun olabilmesinden dolayı yeniden bir puanlama gereği duyulmuştur.

6.7. Problemin Çözümünde Önerilen Matematiksel Model (Suggested Mathematical Model of Problem Solution)

\section{Parametreler:}

$n$ : Fabrikadaki şef sayısı $\quad n=9$

$m$ : Gün sayısı $\quad m=30$

$l$ : Vardiya sayıs $\quad l=3$

$i$ : Şef indeksi, $\quad i=1,2, \ldots, n$.

$j$ : Gün indeksi, $\quad j=1,2, \ldots, m$.

$k$ : Vardiya indeksi $\quad k=1,2, \ldots, l$.

$a_{i}$ : Şeflerin ald $\breve{g ̆}_{1}$ puanlar $\quad i=1,2, \ldots, n$.

\section{Karar Değişkenleri:}

$X_{i j k}$

$=\left\{\begin{array}{rr}1, & i . s ̧ e f j . g u ̈ n d e k i \\ 0, & \text { diğer durumlarda }\end{array}\right.$

$\boldsymbol{h}_{\boldsymbol{i} j}=\left\{\begin{array}{l}1, i . s ̧ e f j . g \text { ünde izinli ise } \\ 0, \quad \text { diğer durumlarda }\end{array}\right.$

Kisitlar:

1.Kısıt: Günlük personel ihtiyacını karşılama kısıtları:

Sabah vardiyası için ihtiyaç duyulan şef sayısı

$\sum_{i=1}^{n} X_{i j 1}=3$

$j=1,2, \ldots, m$

Akşam vardiyası için ihtiyaç duyulan şef sayısı

$\sum_{i=1}^{n} X_{i j 2}=3$

$j=1,2, \ldots, m$

Gece vardiyası için ihtiyaç duyulan şef sayısı

$\sum_{i=1}^{n} X_{i j 3}=1$

$j=1,2, \ldots, m$

2.Kısıt: Her şefi günde sadece bir vardiya atama kısıtı:

$\sum_{k=1}^{l} X_{i j k}<=1$

$i=1,2, \ldots, n$ $j=1,2, \ldots, m$

3.Kısıt: Her şefin izinli olduğu gün çalışmaması kısıtı:

$\sum_{k=1}^{l} X_{i j k}<=\left(1-h_{i j}\right)$

$i=1,2, \ldots, n$ $j=1,2, \ldots, m$

4.Kısıt: Her şef ardı ardına 5 günden fazla çalışmaması kısıtı:

$h_{i j}+h_{i(j+1)}+h_{i(j+2)}+h_{i(j+3)}+h_{i(j+4)}+h_{i(j+5)}>=1$ $i=1,2, \ldots, n \quad j=1,2, \ldots, m-5$

5.Kısıt: Her şefin planlama dönemi boyunca en fazla çalışması gereken vardiya sayılarının belirlenmesi kısıtları:

$\sum_{j=1}^{m} X_{i j 1}<=10$

$i=1,2, \ldots, n$

$\sum_{j=1}^{m} X_{i j 2}<=10$

$i=1,2, \ldots, n$ 
$\sum_{j=1}^{m} X_{i j 3}<=4$

$i=1,2, \ldots, n$

6.Kısıt: Her şefin planlama dönemi boyunca en az çalışması gereken vardiya sayılarının belirlenmesi kısıtları:

$\sum_{j=1}^{m} X_{i j 1}>=9$

$i=1,2, \ldots, n$

$\sum_{j=1}^{m} X_{i j 2}>=9$

$i=1,2, \ldots, n$

$\sum_{j=1}^{m} X_{i j 3}>=3$

$i=1,2, \ldots, n$

7.Kısıt: Herhangi bir şef herhangi bir günde gece vardiyasına atandığı takdirde ertesi gün ki sabah ve akşam vardiyalarına atanmaması kısıtı:

$X_{i j 3}+X_{i(j+1) 1}+X_{i(j+1) 2}<=1 \quad i=1,2, \ldots, n$
$j=1,2, \ldots, m$

8.Kısıt: Herhangi bir şef herhangi bir günde akşam vardiyasına atandığı takdirde ertesi gün ki sabah vardiyasına atanmaması kısıtı:

$$
\begin{gathered}
X_{i j 2}+X_{i(j+1) 1}<=1 \quad i=1,2, \ldots, n \\
j=1,2, \ldots, m
\end{gathered}
$$

\section{Hedef Kisıtları:}

Modelde belirtilen kısıtlara gevşek değişkenler eklenerek istenilen hedeflerin gerçekleşmesi ve sapmaların en küçüklenmesi amaçlanmıştır Modelde 5 tane hedef kısıtı vardır.

Hedef 1: Şefler vardiyalara atanırken izin günüçalışma günü-izin günü olarak atanması en aza indirgenmesi istenen hedef kısıtı:

$h_{i j}+X_{i(j+1) 1}+X_{i(j+1) 2}+X_{i(j+1) 3}+h_{i(j+2)}+d 1_{i j}^{-}-$
$d 1_{i j}^{+}=2 \quad i=1,2, \ldots, n \quad j=1,2, \ldots, m-2$

Hedef 2: Şefler vardiyalara atanırken çalışma günüizin günü-çalışma günü olarak atanması en aza indirgenmesi istenen hedef kısıtı:

$$
\begin{aligned}
& X_{i j 1}+X_{i j 2}+X_{i j 3}+h_{i(j+1)}+X_{i(j+2) 1}+X_{i(j+2) 2}+ \\
& X_{i(j+2) 3}+d 2_{i j}^{-}-d 2_{i j}^{+}=2 \quad i=1,2, \ldots, n j=1,2, \ldots, m-2
\end{aligned}
$$

Hedef 3: Planlama dönemi boyunca her șefin atandığı toplam vardiya sayıları mümkün olduğunca eşit olması istenen hedef kısıtı:

$$
\begin{gathered}
\sum_{j=1}^{m}\left(X_{i j 1}+X_{i j 2}+X_{i j 3}\right)+d 3_{i j}^{-}-d 3_{i j}^{+}=23 \\
i=1,2, \ldots, m
\end{gathered}
$$

Hedef 4: Planlama dönemi boyunca günlük sabah vardiyasına atanan şefler arasında niteliği çok olan ile niteliği az olan şefler mümkün olduğunca aynı vardiyaya atanmasını hedefleyen kısıt:

$$
\begin{gathered}
\sum_{i=1}^{m}\left(a_{i} * X_{i j 1}\right)+d 4_{i j}^{-}-d 4_{i j}^{+}=9 \\
j=1,2, \ldots, m
\end{gathered}
$$

Hedef 5: Planlama dönemi boyunca günlük akșam vardiyasına atanan şefler arasında niteliği çok olan ile niteliği az olan şefler mümkün olduğunca aynı vardiyaya atanmasinı hedefleyen kısit:

$\sum_{i=1}^{m}\left(a_{i} * X_{i j 2}\right)+d 5_{i j}^{-}-d 5_{i j}^{+}=9$

$$
j=1,2, \ldots, m
$$

\begin{tabular}{|c|c|c|c|c|c|c|c|c|c|c|c|c|c|c|c|c|c|c|c|c|c|c|c|c|c|c|c|c|c|c|c|c|c|}
\hline Şef/Gün & 1 & 2 & 3 & 4 & 5 & 6 & 7 & 8 & 9 & 10 & 11 & 12 & 13 & 14 & 15 & 16 & 17 & 18 & 19 & 20 & 21 & 22 & 23 & 24 & 25 & 26 & 27 & 28 & 29 & 30 & \begin{tabular}{l|l}
$\mathbf{S}$ & $\mathrm{A}$ \\
\end{tabular} & \begin{tabular}{l|l}
$A$ & $G$ \\
\end{tabular} & Toplam \\
\hline 1 & $S$ & $S$ & & $S$ & A & & & & A & $\mathrm{A}$ & $\mathrm{G}$ & $\mathrm{G}$ & & $S$ & $G$ & & $S$ & $\mathrm{~A}$ & $\mathrm{~A}$ & & $S$ & $S$ & $S$ & $S$ & $\mathrm{~A}$ & & A & $\mathrm{A}$ & $\mathrm{A}$ & $\mathrm{A}$ & 101 & 10 & 24 \\
\hline 2 & & A & $\mathrm{A}$ & & $S$ & S & $S$ & G & & $S$ & $S$ & & $S$ & $\mathrm{~A}$ & $\mathrm{~A}$ & A & A & & $S$ & $S$ & $\mathrm{~A}$ & A & A & & $S$ & A & $\mathrm{G}$ & $\mathrm{G}$ & & $S$ & & 10 & 23 \\
\hline 3 & A & A & & $S$ & A & A & & $S$ & S & $S$ & $S$ & A & & $S$ & $S$ & G & & $S$ & $S$ & $\mathrm{~A}$ & $\mathrm{~A}$ & A & & $\mathrm{G}$ & $G$ & G & & $S$ & $\mathrm{~A}$ & A & & 10 & 24 \\
\hline 4 & $\mathrm{~A}$ & $\mathrm{G}$ & $\mathrm{G}$ & $\mathrm{G}$ & & S & $S$ & $S$ & S & A & & $S$ & A & $\mathrm{A}$ & $\mathrm{A}$ & A & & $S$ & $\mathrm{~A}$ & $\mathrm{~A}$ & & & $\mathrm{~A}$ & $\mathrm{~A}$ & & $S$ & $S$ & $S$ & $S$ & & & & 23 \\
\hline 5 & $S$ & $S$ & $S$ & & $S$ & A & A & & & A & $\mathrm{A}$ & & $S$ & $\mathrm{~A}$ & $\mathrm{~A}$ & & A & A & $\mathrm{G}$ & $\mathrm{G}$ & $\mathrm{G}$ & & $S$ & $S$ & $S$ & $S$ & $S$ & & $\mathrm{~A}$ & $\mathrm{~A}$ & & 10 & 23 \\
\hline 6 & $G$ & & $S$ & $\mathrm{~A}$ & A & $F$ & $\mathrm{G}$ & & נ & $S$ & $\mathrm{~A}$ & A & A & & $S$ & $S$ & $S$ & $S$ & $\mathrm{~A}$ & & $S$ & $\mathrm{~A}$ & $\mathrm{G}$ & & $\mathrm{A}$ & $\mathrm{A}$ & & $S$ & $S$ & & & 10 & 23 \\
\hline 7 & $\mathrm{~A}$ & & $\mathrm{~A}$ & A & & $S$ & $S$ & A & $\mathrm{G}$ & G & & $S$ & A & G & & $S$ & $S$ & A & & $S$ & $S$ & $S$ & A & $\mathrm{A}$ & & $\mathrm{A}$ & A & & $S$ & $S$ & & 10 & 23 \\
\hline 8 & & $S$ & $S$ & $S$ & $S$ & & A & A & A & & $\mathrm{A}$ & A & $\mathrm{G}$ & & $S$ & $S$ & A & $\mathrm{G}$ & & $\mathrm{A}$ & $\mathrm{A}$ & $\mathrm{G}$ & & $S$ & $S$ & $S$ & A & $\mathrm{A}$ & & $S$ & & 10 & 23 \\
\hline 9 & $S$ & A & A & $\mathrm{A}$ & $\mathrm{G}$ & & A & A & A & & $S$ & $S$ & $S$ & $S$ & & $\mathrm{~A}$ & $G$ & & $S$ & $S$ & & $S$ & $S$ & $\mathrm{~A}$ & $\mathrm{~A}$ & & $S$ & $\mathrm{~A}$ & G & $G$ & & 10 & 24 \\
\hline$S$ & 3 & 3 & 3 & 3 & 3 & 3 & 3 & 3 & 3 & 3 & 3 & 3 & 3 & 3 & 3 & 3 & 3 & 3 & 3 & 3 & 3 & 3 & 3 & 3 & 3 & 3 & 3 & 3 & 3 & 3 & & & \\
\hline A & 3 & 3 & 3 & 3 & 3 & 3 & 3 & 3 & 3 & 3 & 3 & 3 & 3 & 3 & 3 & 3 & 3 & 3 & 3 & 3 & 3 & 3 & 3 & 3 & 3 & 3 & 3 & 3 & 3 & 3 & & & \\
\hline G & 1 & 1 & 1 & 1 & 1 & 1 & 1 & 1 & 1 & 1 & 1 & 1 & 1 & 1 & 1 & 1 & 1 & 1 & 1 & 1 & 1 & 1 & 1 & 1 & 1 & 1 & 1 & 1 & 1 & 1 & & & \\
\hline
\end{tabular}

Amaç Fonksiyonu:

$$
\begin{aligned}
\operatorname{MinZ}=\sum_{i=1}^{n} \sum_{j=1}^{m} & \left(d 3_{i j}^{-}-d 3_{i j}^{+}\right)+\left(d 2_{i j}^{-}-d 2_{i j}^{+}\right) \\
& +\left(d 1_{i j}^{-}-d 1_{i j}^{+}\right)+\sum_{j=1}^{m} d 4_{j}^{-}+d 5_{j}^{-}
\end{aligned}
$$

Modelin çözümünde "Intel (R) Core (TM) i5-3210 M CPU@2.50 GH” işlemcisi, 8 GB belleği ve Windows 10 işletim sistemine sahip bilgisayar kullanılmıştır. İlgili verilerin girilmesiyle model ILOG CPLEX Studio IDE programında yazılmış ve CPLEX çözücüsü ile çözülmüştür.

Şekil 2. Şefler için oluşturulan çalışma çizelgesi (The work schedule is created for Chief) 


\begin{tabular}{|c|c|c|c|c|c|c|c|c|c|c|c|c|c|c|c|c|c|c|c|c|c|c|c|c|c|c|c|c|c|c|}
\hline Sabah & $\mathbf{1}$ & $\mathbf{2}$ & $\mathbf{3}$ & $\mathbf{4}$ & $\mathbf{5}$ & $\mathbf{6}$ & $\mathbf{7}$ & $\mathbf{8}$ & $\mathbf{9}$ & $\mathbf{1 0}$ & $\mathbf{1 1}$ & $\mathbf{1 2}$ & $\mathbf{1 3}$ & $\mathbf{1 4}$ & $\mathbf{1 5}$ & $\mathbf{1 6}$ & $\mathbf{1 7}$ & $\mathbf{1 8}$ & $\mathbf{1 9}$ & $\mathbf{2 0}$ & $\mathbf{2 1}$ & $\mathbf{2 2}$ & $\mathbf{2 3}$ & $\mathbf{2 4}$ & $\mathbf{2 5}$ & $\mathbf{2 6}$ & $\mathbf{2 7}$ & $\mathbf{2 8}$ & $\mathbf{2 9}$ & $\mathbf{3 0}$ \\
\hline C..N & 1 & 1 & 1 & 1 & 1 & 1 & 1 & 1 & 1 & 1 & 1 & 1 & 1 & 1 & 1 & 1 & 1 & 1 & 1 & 1 & 1 & 1 & 1 & 1 & 1 & 1 & 1 & 1 & 1 & 1 \\
\hline $\mathbf{0 . N}$ & 1 & 1 & & 1 & 1 & 1 & 1 & 1 & & 1 & 1 & & 1 & 1 & & & 1 & & 1 & 1 & 1 & 1 & 1 & 1 & 1 & & & & & 1 \\
\hline A.N & 1 & 1 & 2 & 1 & 1 & 1 & 1 & 1 & 2 & 1 & 1 & 2 & 1 & 1 & 2 & 2 & 1 & 2 & 1 & 1 & 1 & 1 & 1 & 1 & 1 & 2 & 2 & 2 & 2 & 1 \\
\hline
\end{tabular}

\begin{tabular}{|c|c|c|c|c|c|c|c|c|c|c|c|c|c|c|c|c|c|c|c|c|c|c|c|c|c|c|c|c|c|c|}
\hline Akşam & . & 2 & 3 & 4 & 5 & 6 & 7 & 8 & $y$ & 10 & 11 & 12 & 13 & 14 & 15 & 16 & 17 & 18 & 19 & 20 & 21 & 22 & 23 & 24 & 25 & 26 & 27 & 28 & & 30 \\
\hline C.N & 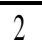 & 1 & 1 & 1 & 1 & 2 & 1 & 1 & & 1 & 1 & 1 & 1 & 1 & 1 & & 1 & 2 & & 1 & 1 & 1 & 1 & 1 & & 1 & 1 & & 2 & 2 \\
\hline 0.1 & & 1 & 1 & & 1 & & & & 1 & 1 & & & & 1 & 1 & 1 & 1 & 1 & 1 & & 1 & 1 & 1 & & 1 & 1 & 1 & 1 & 1 & \\
\hline A.N & & 1 & 1 & 2 & 1 & 1 & 2 & 2 & & 1 & 2 & 2 & 12 & & 1 & 2 & & & & & 1 & 1 & 1 & 2 & 2 & 1 & 1 & 2 & & \\
\hline
\end{tabular}

Şekil 3. Niteliklerine göre sınıflandırılan şeflerin günlük atandığı vardiyalar (The chef is assigned daily shifts are classified according to their quality)

Nitelikler Ç.N: Çok Nitelikli O.N: Orta Nitelikli A.N: Az Nitelikli

\begin{tabular}{|c|c|c|c|c|c|c|c|c|c|c|c|c|c|c|c|c|c|c|}
\hline Vardigy & \begin{tabular}{l|l}
1 & 2
\end{tabular} & & & 6 & 8 & & 10 & & \begin{tabular}{|l|l|}
13 & 14 \\
\end{tabular} & \begin{tabular}{|l|l|}
15 & 16 \\
\end{tabular} & \begin{tabular}{|l|l|l}
17 & 18 \\
\end{tabular} & $\mid 1921$ & 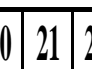 & $2 \mid 23$ & 242 & & 2728 & \begin{tabular}{|l|l|l|}
80 & 30
\end{tabular} \\
\hline $\bar{S}$ & \begin{tabular}{l|l}
9 & 9
\end{tabular} & & \begin{tabular}{l|l}
9 & 9
\end{tabular} & 9 & & $\overline{9}$ & \begin{tabular}{|l|}
9 \\
\end{tabular} & 9 & \begin{tabular}{|l|l|}
9 & 9 \\
\end{tabular} & & \begin{tabular}{|l|}
9 \\
\end{tabular} & & & 99 & $\begin{array}{l}9 \\
9\end{array}$ & & 7 & 9 \\
\hline A & \begin{tabular}{l|l}
11 & 9
\end{tabular} & & \begin{tabular}{l|l}
7 & 9
\end{tabular} & 11 & & 75 & \begin{tabular}{|l|}
9 \\
\end{tabular} & & \begin{tabular}{|l|l|}
7 & 9 \\
\end{tabular} & 9 & \begin{tabular}{|l|l|l|}
9 & 13
\end{tabular} & & 9 & \begin{tabular}{|l|l|}
9 & \\
\end{tabular} & & & 9 & $5 \mid 13$ \\
\hline
\end{tabular}

Şekil 4. Niteliklerine göre sınıflandırılan şeflerin günlük atandığı vardiyalardaki toplam puanları (Total points in the assigned day shift supervisor of classified according to their quality)

Vardiyalar S: Sabah A: Akşam

Yapılan çalışmanın sonuçları Şekil 2, Şekil 3 ve Şekil 4'te verilmiştir.

Şekil 2'de gösterilen pembe renkteki şefler çok nitelikli, yeşil renkteki şefler orta nitelikli, sarı renkte gösterilen şefler ise az nitelikli şefleri göstermektedir. Bu çizelgede her gün ihtiyaç duyulan șef sayıları, her şefin aylık atandığı vardiyalar ve toplam vardiya sayıları gösterilmiştir. Şeflerin dengeli ve adaletli bir şekilde atanması hedefine ulaşılmıştır.

Şekil 3'te AHP yöntemi ile niteliklerine göre sınıflandırılan şeflerin sabah ve akşam vardiyalarına niteliği çok olan ile niteliği az olan şefler aynı vardiyaya atanması hedefinin olabildiğince sağlandığını göstermektedir.

Şekil 4'te sabah ve akşam vardiyasına atanan şeflerin puanlarının toplamıdır yani çok nitelikli şef 5 puan, orta nitelikli şef 3 puan ve az nitelikli şef 1 puan değerlerini baz alarak şeflerin atandığı vardiyaya göre istenilen hedef puanlarının ne kadar gerçekleştiğini göstermektedir.

\section{SONUÇLAR (RESULTS)}

$\mathrm{Bu}$ çalışmada bir fabrikada çalışan şeflerin aylık çalışma süresi boyunca fabrikanın belirlediği vardiyalara dengeli ve adaletli bir șeklide atanması sağlanmıștır ve dahası diğer çalışmalardan farklı olarak AHP yöntemini ile şefleri belirli kriterler kapsamında niteliklerine göre sınıflandııılmıştır. Bu sınıflandırılan şefleri daha sonra günlük sabah ve akşam vardiyalarına niteliklerine göre atamalar yaparak fabrikadaki verimliliğini artırılmasında ve şeflerin birbirlerini tamamlanması konusunda önemli bir rol oynanmıştır.

Çalışmanın çözümü için tam sayılı programlama ve hedef programlama kullanılmıştır ve istenilen 5 hedef kısıtı vardır. Yapılan diğer çalışmalar incelendiğinde önerilen model ile alakalı çok fazla çalışma tespit edilememiştir.

Bundan sonraki çalışmalarda daha farklı kısıtlar kullanılarak fabrikada çalışan başka personellerin çizelgelenmesi yapılabilir. Planlanması yapılan personelin istek ve önerileri modele eklenerek daha farklı çalışmalar yapılabilir.

\section{KAYNAKLAR (REFERENCES)}

[1] S. Topaloglu, I. Ozkarahan, An implicit goal programming model for the tour scheduling problem considering the employee work preferences. Annals of Operations Research, 128, 135-158, 2004.

[2] A. T. Ernst, H. Jiang, M. Krishnamoorthy, B. Owens, D. Sier, An annotated bibliography of personnel scheduling and rostering. Annals of Operations Research, 127, 21- 144, 2004.

[3] G. B. Dantzig, Letter to the editor-A comment on Edie's "Traffic delays at toll booths". Operations Research, 2, 339-341, 1954.

[4] L. C. Edie, Traffic delays at toll booths. Operations Research, 2, 107-138, 1954.

[5] J. Ignizio, Introduction to goal programming, Sage Publications Inc., Beverley Hills, California, USA, 1985. 
[6] A. Charnes, W. W. Cooper, R. Ferguson, Optimal estimation of executive compensation by linear programming, Management Science, 1, 138-151, 1955

[7] A. Charnes, W.W. Cooper, Management models and industrial applications of linear programming", Wiley, New York, 1965-66, 1, and 1967, 2, 1961.

[8] A. Charnes, W.W. Cooper, Goal programming and multiple objective optimizations, European Journal of Operational Research I, 39-54, 1977.

[9] M. Aly, O. Louly, A goal programming model for staff scheduling at a telecommunications center, J Math Model Algor, 12,167-178,2012.

[10] M. N. Azaiez, S. S. Al Sharif, A 0-1 goal programming model for nurse scheduling. Computers \& Operations Research, 32, 491-507, 2005.

[11] G. Bektur, S. Hasgül, Kıdem seviyelerine göre işgücü çizelgeleme problemi: Hizmet sektöründe bir uygulama. Afyon Kocatepe Üniversitesi, İIBF Dergisi,385-402, 2013.

[12] S. C. K. Chu, Generating, scheduling and rostering of shift crew-duties: Applications at the Hong Kong International Airport. European Journal of Operational Research, 177, 1764- 1778, 2007.

[13] A. Elomri, S. Elthlatiny, Z.S. Mohamed, A goal Programming model for fairly scheduling medicine residents. Int. J Sup. Chain. Mgt, IJSCM, 4, 20507399, 2015.

[14] L. Hung-Tso, C. Yen-Ting, C. Tsung-Yu, L. YiChun, Crew rostering with multiple goals: An empirical study. Computers \& Industrial Engineering, 63, 483-493, 2012.

[15] H. Sulak, M. Bayhan, A Model suggestion and an application for nurse scheduling problem. Journal of Research in Business, Economics and Management, 2395-2210, 2016.

[16] S. Topaloglu, A shift scheduling model for employees with different seniority levels and an application in healthcare. European Journal of Operational Research, 198, 943 957, 2009.

[17] T. L. Saaty, The Analytic Hierarchy Process, McGraw-Hill Inc., New York, 1977.

[18] T.L. Saaty, How to make a decision: the analytic hierarchy process ${ }^{e}$, European Journal of Operational Research, 48, 9-26, 1990.

[19] C. S. Azmat, T. Hurlimann, M. Widmer, Mixed integer programming to schedule a single-shift workforce under annualized hours. Annals of Operations Research, 128, 199-215, 2004.

[20] A. Volgenant, A note on the assignment problem with seniority and job priority constraints. European Journal of Operational Research, 154, 330-335, 2004.
[21] H. K. Alfares, Compressed workweek scheduling with days-off consecutivity weekendoff frequency and work stretch constraints. Infor, 44, 175-189, 2006.

[22] S. M. Al-Yakoob, H. D. Sherali, Mixed-integer programming models for an employee scheduling problem with multiple shifts and work locations. Annals of Operations Research, 155, 119-142, 2007.

[23] S. U. Seckiner, H. Gokcen, M. Kurt, An integer programming model for hierarchical workforce scheduling problem. European Journal of Operational Research, 183, 694-699, 2007.

[24] D. Sinreich, O. Jabali, Staggered work shifts: a way to downsize and restructure an emergency department workforce yet maintain current operational performance. Health Care Management Science, 10, 293-308, 2007.

[25] B. Sungur, Bir güzellik salonunun tur çizelgeleme problemi için karma tamsayılı hedef programlama modelinin geliştirilmesi. İstanbul Üniversitesi İşletme Fakültesi Dergisi Istanbul University Journal of the School of Business Administration , 1, 49-64, 2008.

[26] B. Sungur, Hiyerarşik işgücü çizelgeleme problemi için tamsayılı programlama modeli. Dokuz Eylül Üniversitesi İktisadi ve İdari Bilimler Fakültesi Dergisi, 24, 2, 23-31, 2009.

[27] A. Y. Rong, Monthly tour scheduling models with mixed skills considering weekend off requirements. Computers \& Industrial Engineering, 59, 334-343, 2010.

[28] N. Bağ, M. Özdemir, T. Eren, 0-1 hedef programlama ve ANP yöntemi ile hemşire çizelgeleme problemi çözümü. International Journal of Engineering Research and Development,1,2-6, 2012.

[29] B. A. Kassa, A. E. Tizazu, Personnel scheduling using an integer programming model- an application at Avanti Blue-Nile Hotels. SpringerPlus, 2:333, 17, 2013.

[30] Y. Öztürkoğlu, F. Çalışkan, Hemşire çizelgelenmesinde esnek vardiya planlanması ve hastane uygulaması. Dokuz Eylül Üniversitesi Sosyal Bilimler Enstitüsü Dergisi 16,1,115-133, 2014.

[31] L. Hidri, M. Labidi, Optimal physicians schedule in an Intensive Care Unit. IOP Conf. Series: Materials Science and Engineering 131, 1-8, 2016.

[32] F.M. Unal, T. Eren, Hedef programlama ile nöbet çizelgeleme probleminin çözümü. Akademik Platform Mühendislik ve Fen Bilimleri Dergisi, 4, 1, 28-37, 2016. 
EK 1:

Kullanılan Kriterler için Karşılaştırma Matrisi (Comparison Matrix for Criteria)

\begin{tabular}{|c|c|c|c|c|c|}
\hline Kriterler & Tecrübe Yılı & $\begin{array}{c}\text { Sertifikalar ve } \\
\text { Eğitim Kurslar }\end{array}$ & Aile Yapısı & $\begin{array}{c}\text { Fabrikadaki Çalıştı̆̆ı } \\
\text { Yıl }\end{array}$ & $\begin{array}{c}\text { İletişim } \\
\text { Becerisi }\end{array}$ \\
\hline Tecrübe Yılı & 1 & 3 & 9 & 5 & 7 \\
\hline $\begin{array}{c}\text { Sertifikalar ve } \\
\text { Ĕgitim Kursırı }\end{array}$ & 0,33 & 1 & 7 & 3 & 5 \\
\hline Aile Yapısı & 0,11 & 0,14 & 1 & 0,2 & 3 \\
\hline $\begin{array}{c}\text { Fabrikadaki Çalıştığı } \\
\text { Yıl }\end{array}$ & 0,2 & 0,33 & 5 & 1 & 3 \\
\hline İletişim Becerisi & 0,14 & 0,2 & 3 & 0,33 & 1 \\
\hline
\end{tabular}

Şeflerin Tecrübe Yıllarına Göre Karşılaştırma Matrisi (Comparison Matrix According to Chiefs' Experiences of Years)

\begin{tabular}{|c|c|c|c|c|c|c|c|c|c|}
\hline Şefler & $\mathbf{1}$ & $\mathbf{2}$ & $\mathbf{3}$ & $\mathbf{4}$ & $\mathbf{5}$ & $\mathbf{6}$ & $\mathbf{7}$ & $\mathbf{8}$ & $\mathbf{9}$ \\
\hline $\mathbf{1}$ & 1 & 1 & 0,33 & 3 & 0,2 & 3 & & 0,2 & 3 \\
\hline $\mathbf{2}$ & 1 & 1 & 0,33 & 3 & 0,2 & 3 & 0,2 & 3 & 3 \\
\hline $\mathbf{3}$ & 3 & 3 & 1 & 5 & 0,33 & 5 & 0,33 & 5 & 5 \\
\hline $\mathbf{4}$ & 0,33 & 0,33 & 0,2 & 1 & 0,14 & 1 & 0,2 & 1 & 1 \\
\hline $\mathbf{5}$ & 5 & 5 & 3 & 7 & 1 & 7 & 1 & 7 & 7 \\
\hline $\mathbf{6}$ & 0,33 & 0,33 & 0,2 & 1 & 0,14 & 1 & 0,14 & 1 & 1 \\
\hline $\mathbf{7}$ & 5 & 5 & 3 & 5 & 1 & 7 & 1 & 7 & 7 \\
\hline $\mathbf{8}$ & 0,33 & 0,33 & 0,2 & 1 & 0,14 & 1 & 0,14 & 1 & 1 \\
\hline $\mathbf{9}$ & 0,33 & 0,33 & 0,2 & 1 & 0,14 & 1 & 0,14 & 1 & 1 \\
\hline
\end{tabular}

Şeflerin Aldığı Sertifikalara Göre Karşılaştırma Matrisi (Comparison Matrix According to the certificate received the Chiefs)

\begin{tabular}{|c|c|c|c|c|c|c|c|c|c|}
\hline Şefler & $\mathbf{1}$ & $\mathbf{2}$ & $\mathbf{3}$ & $\mathbf{4}$ & $\mathbf{5}$ & $\mathbf{6}$ & $\mathbf{7}$ & $\mathbf{8}$ & $\mathbf{9}$ \\
\hline $\mathbf{1}$ & 1 & 1 & 1 & 1 & 0,33 & 3 & 1 & 1 & 3 \\
\hline $\mathbf{2}$ & 1 & 1 & 1 & 1 & 0,33 & 3 & 1 & 1 & 3 \\
\hline $\mathbf{3}$ & 1 & 1 & 1 & 1 & 0,33 & 3 & 1 & 1 & 3 \\
\hline $\mathbf{4}$ & 1 & 1 & 1 & 1 & 0,33 & 3 & 1 & 1 & 3 \\
\hline $\mathbf{5}$ & 3 & 3 & 3 & 3 & 1 & 5 & 3 & 3 & 5 \\
\hline $\mathbf{6}$ & 0,33 & 0,33 & 0,33 & 0,33 & 0,2 & 1 & 0,33 & 0,33 & 1 \\
\hline $\mathbf{7}$ & 1 & 1 & 1 & 1 & 0,33 & 3 & 1 & 1 & 3 \\
\hline $\mathbf{8}$ & 1 & 1 & 1 & 1 & 0,33 & 3 & 1 & 1 & 3 \\
\hline $\mathbf{9}$ & 0,33 & 0,33 & 0,33 & 0,33 & 0,2 & 1 & 0,33 & 0,33 & 1 \\
\hline
\end{tabular}


Şeflerin Aile Yapılarına Göre Karşılaştırma Matrisi (Comparison Matrix of Chiefs by Family Constructs)

\begin{tabular}{|c|c|c|c|c|c|c|c|c|c|}
\hline Şefler & $\mathbf{1}$ & $\mathbf{2}$ & $\mathbf{3}$ & $\mathbf{4}$ & $\mathbf{5}$ & $\mathbf{6}$ & $\mathbf{7}$ & $\mathbf{8}$ & $\mathbf{9}$ \\
\hline $\mathbf{1}$ & 1 & 3 & 1 & 0,33 & 3 & 3 & 1 & 1 & 3 \\
\hline $\mathbf{2}$ & 0,33 & 1 & 0,33 & 0,2 & 1 & 1 & 0,33 & 0,33 & 1 \\
\hline $\mathbf{3}$ & 1 & 3 & 1 & 0,33 & 3 & 3 & 1 & 1 & 3 \\
\hline $\mathbf{4}$ & 3 & 5 & 3 & 1 & 5 & 5 & 3 & 3 & 5 \\
\hline $\mathbf{5}$ & 0,33 & 1 & 0,33 & 0,2 & 1 & 1 & 0,33 & 0,33 & 1 \\
\hline $\mathbf{6}$ & 0,33 & 1 & 0,33 & 0,2 & 1 & 1 & 0,33 & 0,33 & 1 \\
\hline $\mathbf{7}$ & 1 & 3 & 1 & 0,33 & 3 & 3 & 1 & 1 & 3 \\
\hline $\mathbf{8}$ & 1 & 3 & 1 & 0,33 & 3 & 3 & 1 & 1 & 3 \\
\hline $\mathbf{9}$ & 0,33 & 1 & 0,33 & 0,2 & 1 & 1 & 0,33 & 0,33 & 1 \\
\hline
\end{tabular}

Şeflerin Fabrikadaki Çalıştığı Yıllara Göre Karşılaştırma Matrisi (Comparison Matrix by years worked as chief of the Factory)

\begin{tabular}{|c|c|c|c|c|c|c|c|c|c|}
\hline Şefler & $\mathbf{1}$ & $\mathbf{2}$ & $\mathbf{3}$ & $\mathbf{4}$ & $\mathbf{5}$ & $\mathbf{6}$ & $\mathbf{7}$ & $\mathbf{8}$ & $\mathbf{9}$ \\
\hline $\mathbf{1}$ & 1 & 3 & 0,33 & 1 & 0,14 & 0,33 & 0,2 & 1 & 3 \\
\hline $\mathbf{2}$ & 0,33 & 1 & 0,2 & 0,33 & 0,11 & 0,2 & 0,14 & 0,33 & 1 \\
\hline $\mathbf{3}$ & 3 & 5 & 1 & 3 & 0,2 & 1 & 0,33 & 3 & 5 \\
\hline $\mathbf{4}$ & 1 & 3 & 0,33 & 1 & 0,14 & 0,33 & 0,2 & 1 & 3 \\
\hline $\mathbf{5}$ & 7 & 9 & 5 & 7 & 1 & 5 & 3 & 7 & 9 \\
\hline $\mathbf{6}$ & 3 & 5 & 1 & 3 & 0,2 & 1 & 0,33 & 3 & 5 \\
\hline $\mathbf{7}$ & 5 & 7 & 3 & 5 & 0,33 & 3 & 1 & 5 & 7 \\
\hline $\mathbf{8}$ & 1 & 3 & 0,33 & 1 & 0,14 & 0,33 & 0,2 & 1 & 3 \\
\hline $\mathbf{9}$ & 0,33 & 1 & 0,2 & 0,33 & 0,11 & 0,2 & 0,14 & 0,33 & 1 \\
\hline
\end{tabular}

Şeflerin İletişim Becerilerine Göre Karşılaştırma Matrisi (Comparisons of Chiefs' Communication Skills)

\begin{tabular}{|c|c|c|c|c|c|c|c|c|c|}
\hline Şefler & $\mathbf{1}$ & $\mathbf{2}$ & $\mathbf{3}$ & $\mathbf{4}$ & $\mathbf{5}$ & $\mathbf{6}$ & $\mathbf{7}$ & $\mathbf{8}$ & $\mathbf{9}$ \\
\hline $\mathbf{1}$ & 1 & 3 & 0,33 & 5 & 1 & 0,2 & 1 & 3 & 5 \\
\hline $\mathbf{2}$ & 0,33 & 1 & 0,2 & 3 & 0,33 & 0,14 & 0,33 & 1 & 3 \\
\hline $\mathbf{3}$ & 3 & 5 & 1 & 7 & 3 & 0,33 & 3 & 5 & 7 \\
\hline $\mathbf{4}$ & 0,2 & 0,33 & 0,14 & 1 & 0,2 & 0,11 & 0,2 & 0,33 & 1 \\
\hline $\mathbf{5}$ & 1 & 3 & 0,33 & 5 & 1 & 0,2 & 1 & 3 & 5 \\
\hline $\mathbf{6}$ & 5 & 7 & 3 & 9 & 5 & 1 & 5 & 7 & 9 \\
\hline $\mathbf{7}$ & 1 & 3 & 0,33 & 5 & 1 & 0,2 & 1 & 3 & 5 \\
\hline $\mathbf{8}$ & 0,33 & 1 & 0,2 & 3 & 0,33 & 0,14 & 0,33 & 1 & 3 \\
\hline $\mathbf{9}$ & 0,2 & 0,33 & 0,14 & 1 & 0,2 & 0,11 & 0,2 & 0,33 & 1 \\
\hline
\end{tabular}

